\title{
Sildenafil in the treatment of pulmonary hypertension
}

\author{
Christopher F Barnett ${ }^{1,2}$ \\ Roberto F Machado ${ }^{1,2}$ \\ 'Critical Care Medicine Department, \\ Clinical Center, National Institutes of \\ Health, Bethesda, MD, USA; ${ }^{2}$ Vascular \\ Medicine Branch, National Heart \\ Lung and Blood Institute, National \\ Institutes of Health, Bethesda, MD, \\ USA
}

\begin{abstract}
The therapy of pulmonary hypertension has evolved rapidly in the last 10 years from the use of non-selective vasodilators to drugs that specifically target pulmonary vasodilation, endothelial function, and vascular remodeling. Sildenafil is a phosphodiesterase type 5 inhibitor that has an expanding role in the treatment of pulmonary hypertension. Case series and small studies, as well as the first large randomized controlled trial, have demonstrated the safety and efficacy of sildenafil in improving mean pulmonary artery pressure, pulmonary vascular resistance, cardiac index, and exercise tolerance in pulmonary arterial hypertension. It may be useful in adults, children, and neonates after cardiac surgery, with left heart failure, in fibrotic pulmonary disease, high altitude exposure, and thromboembolic disease, and in combination with other therapies for pulmonary hypertension, such as inhaled iloprost. The oral formulation and favorable adverse effect profile make sildenafil an attractive alternative in the treatment of selected patients with pulmonary hypertension.
\end{abstract}

Keywords: sildenafil, phosphodiesterase inhibitor, pulmonary hypertension, right heart failure

\section{Introduction}

The development of sildenafil began in 1986 when chemists at Pfizer searching for a compound to treat hypertension chose to target augmentation of the renal tubular activity of atrial natriuretic peptide through its second messenger cyclic guanosine monophosphate (cGMP) and the phosphodiesterase (PDE) family of enzymes (Kling 1998). Test compounds were shown to antagonize the activity of PDE 5, resulting in vasodilation and platelet inhibition, turning their focus to treatment of angina. Trials in angina were disappointing but some patients reported the surprising and unexpected side-effect of penile erections (Morales et al 1998), leading to its development as a treatment for erectile dysfunction. As understanding of the mechanism of sildenafil grew, a role in the treatment of pulmonary hypertension $(\mathrm{PH})$ was postulated, eventually leading to the recent Super-1 trial and FDA approval for this indication. Sildenafil is administered orally, is well tolerated with few drug interactions, and does not require intensive monitoring, making it an attractive alternative to other drugs for the treatment of $\mathrm{PH}$. In this article, we review the growing role of sildenafil in the treatment of $\mathrm{PH}$.

\section{PH pathogenesis and clinical course}

Pulmonary hypertension is a general term for a disease process resulting in a progressive increase in the mean pulmonary artery pressure (mPAP) (mPAP $\geq 25 \mathrm{mmHg}$ at rest or $\geq 30 \mathrm{mmHg}$ with exercise) (Barst et al 2004). According to the World Health Organization Revised Clinical Classification of Venice (Simonneau et al 2004), pulmonary arterial hypertension (PAH) is a specific subtype of $\mathrm{PH}$ with a pulmonary capillary wedge pressure $(\mathrm{PCWP}) \leq 15 \mathrm{mmHg}$ and by pulmonary vascular resistance $(\mathrm{PVR})>3$ wood units. PAH can be idiopathic, familial, or secondary to a variety of conditions such as connective tissue disease, hemoglobinopathies, or HIV infection (Table 1). 
Table I Revised clinical classification of pulmonary hypertension

\begin{tabular}{|c|c|c|}
\hline \multicolumn{3}{|c|}{. Pulmonary arterial hypertension (PAH) } \\
\hline I.I & \multicolumn{2}{|c|}{ Idiopathic (IPAH) } \\
\hline 1.2 & \multicolumn{2}{|c|}{ Familial (FPAH) } \\
\hline 1.3 & \multicolumn{2}{|c|}{ Associated with (APAH): } \\
\hline & I.3.1 & Collagen vascular disease \\
\hline & 1.3 .2 & Congenital systemic-to-pulmonary shunts \\
\hline & 1.3 .3 & Portal hypertension \\
\hline & I.3.4 & HIV infection \\
\hline & 1.3 .5 & Drugs and toxins \\
\hline & 1.3.6 & $\begin{array}{l}\text { Other (thyroid disorders, glycogen storage disease, Gaucher disease, hereditary hemorrhagic telangiectasia, } \\
\text { hemoglobinopathies, myeloproliferative disorders, splenectomy) }\end{array}$ \\
\hline \multirow[t]{3}{*}{1.4} & \multicolumn{2}{|r|}{ Associated with significant venous or capillary involvement } \\
\hline & I.4.I & Pulmonary veno-occlusive disease (PVOD) \\
\hline & I.4.2 & Pulmonary capillary hemangiomatosis $(\mathrm{PCH})$ \\
\hline 1.5 & \multicolumn{2}{|c|}{ Persistent pulmonary hypertension of the newborn } \\
\hline
\end{tabular}

2 Pulmonary hypertension $(\mathrm{PH})$ with left heart disease

2.I Left-sided atrial or ventricular heart disease

2.2 Left-sided valvular heart disease

3. $\mathrm{PH}$ associated with lung disease and/or hypoxemia

3.I Chronic obstructive pulmonary disease

3.2 Intersitial lung disease

3.3 Sleep-disordered breathing

3.4 Alveolar hypoventilation disorders

3.5 Chronic exposure to high altitude

3.6 Development abnormalities

4. PH due to chronic thrombotic and/or embolic disease

4.I Thromboembolic obstruction of proximal pulmonary arteries

4.2 Thromboembolic obstruction of distal pulmonary arteries

4.3 Non-thrombotic pulmonary embolism (tumor, parasites, foreign material)

5. Miscellaneous

Sarcoidosis, pulmonary Langerhans cell histiocytosis, lymphangiomatosis, compression of pulmonary vessels by adenopathy, tumor fibrosing mediastinitis, or other process

Adapted with permission from Simonneau G, Galie N, Rubin LJ, et al. 2004. Clinical classification of pulmonary hypertension. J Am Coll Cardiol, 43:5S-12S. @ 2004 Elsevier.

Endothelial dysfunction resulting from an imbalance of endogenous vasoconstrictors (eg, endothelin-1) and vasodilators (eg, nitric oxide [NO], prostacyclin) is thought to lead to vascular constriction, in situ thrombosis, and progressive remodeling of the pulmonary arteries (Pietra et al 1989; Rubin 1997). Vascular remodeling in PAH is characterized by distal pulmonary arterial smooth muscle cell hypertrophy and proliferation with subsequent luminal narrowing and development of plexiform lesions. Regardless of the etiology, the pathologic appearance is remarkably similar, suggesting an underlying, common disease pathway (Galiè et al 1998).

Patients with $\mathrm{PH}$ often present with signs and symptoms of right heart failure. Diagnostic evaluation includes a search for any underlying diseases followed by right heart catheterization for the measurement of mPAP, PCWP, and PVR, and performance of vasodilator testing. The 6 minute walk test is performed at baseline and on follow up to track exercise capacity and assess disease severity (Miyamoto et al 2000; McLaughlin et al 2002; Hoeper et al 2004).

\section{Therapies for $\mathrm{PH}$}

Prior to the advent of vasodilator therapy, progressive rightsided heart failure frequently lead to death within 2-3 years (D’Alonzo et al 1991). Calcium channel blockers were the first drugs shown to benefit patients with idiopathic PAH (Rich et al 1992) and remain first-line therapy in the few patients who respond during vasodilator testing (Sitbon et al 2005). Based on autopsy findings of frequent undetected pulmonary thrombi (Fuster et al 1984) and a small retrospective series showing increased transplant-free survival in anticoagulated patients, treatment with warfarin has also become a part of standard therapy. The use of diuretics and digoxin can help relieve symptoms of right heart failure.

In 1996, intravenous epoprostenol was shown in a randomized controlled trial to improve exercise tolerance, hemodynamics, and survival in PAH (Barst et al 1996). Prostacyclin and other prostanoids are administered by continuous intravenous or subcutaneous infusion, inhalation, or orally. Treatment may be complicated by systemic 
vasodilation resulting in hypotension, headache and jaw pain, or hypoxemia due to ventilation/perfusion (V/Q) mismatch, or right to left shunting (Rubin 1997; Castro et al 1998). Other potential adverse effects include infections, thrombosis, and malfunction of the delivery system resulting in pulmonary hypertensive crisis (Barst et al 1996).

Two randomized trials have shown significant improvements in 6 minute walk distance, hemodynamics, and time to clinical worsening during treatment with the oral endothelin $\mathrm{A} / \mathrm{B}$ receptor antagonist bosentan (Channick et al 2001; Rubin et al 2002). The most common adverse effect is a dose-related elevation in liver enzymes that can occur in up to $11 \%$ of patients and necessitate cessation of therapy (Lee and Channick 2005).

\section{Pharmacology and acute effects of sildenafil in $\mathbf{P H}$}

Sildenafil is a selective and potent inhibitor of PDE type 5 which specifically degrades cyclic guanosine monophosphate and is found in high concentrations in pulmonary arteries and the corpora cavernosum (Rabe et al 1994; Ahn et al 1991; Boolell et al 1996; Pauvert et al 2002; Pauvert et al 2003). Normally, endothelium-derived NO stimulates intracellular soluble guanylate cyclase resulting in increased levels of cGMP, which then acts to mediate smooth muscle relaxation (Figure 1). Sildenafil inhibits the degradation of cGMP by PDE 5 and prolongs the actions of cGMP.

Metabolism of sildenafil occurs primarily by hepatic cytochrome P450 enzymes yielding one active metabolite with a potency of approximately $50 \%$ of the parent drug. Patients with age greater than 65 , with creatinine clearance less than 30, and with hepatic cirrhosis have reduced clearance of sildenafil.

During trials for erectile dysfunction, sildenafil was administered to more than 3700 patients worldwide with over 550 patients treated for more than one year. Adverse events included headache $16 \%$, flushing $10 \%$, dyspepsia

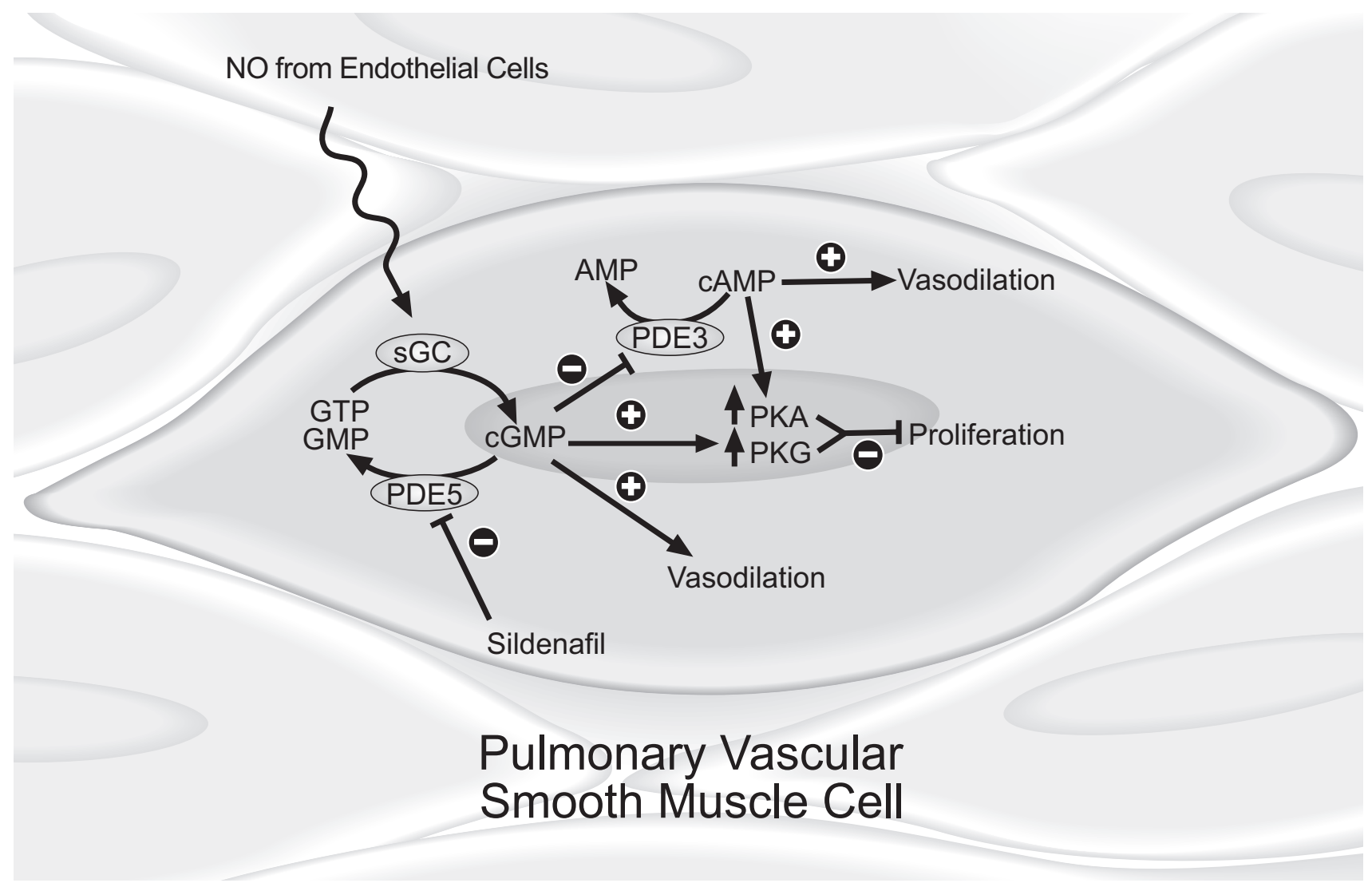

Figure I Mechanism of vasodilatory and antiproliferative effects of sildenafil. NO from vascular endothelial cells stimulates the activity of sGC which produces cGMP from GTP. Sildenafil inhibits the breakdown of cGMP to GMP by PDE 5, increasing cellular concentrations of cGMP which increases the formation of PKG. Competitive inhibition of PDE inhibits breakdown of CAMP which stimulates increased production of PKA. Vasodilation results primarily from modulation of ion channel activity by cGMP with a lesser contribution from increased levels of cAMP. Inhibition of smooth muscle cell proliferation occurs via increased levels of PKA and PKG.

Abbreviations: AMP, adenosine monophosphate; cAMP, cyclic adenosine monophosphate; cGMP, cyclic guanosine monophosphate; GMP, guanosine monophosphate; GTP, guanosine triphosphate; NO, nitric oxide; PDE 5, phosphodiesterase type 5, PKA, cAMP dependent protein kinase; PKG, cGMP dependent protein kinase; sGC, soluble guanylate cyclase. 
$7 \%$, and nasal congestion $4 \%$ and were similar to those reported in the largest trial of sildenafil in PAH (Galiè et al 2005). Sildenafil leads to a small, usually clinically insignificant drop in blood pressure (Kloner 2004). Cases of vision loss due to non-arteritic anterior ischemic optic neuropathy (NAION) have been reported (McGwin et al 2006), but have not occurred during studies of pulmonary hypertension (Galiè et al 2005; Machado et al 2005). Inhibition of the hepatic P450 enzyme system can potentiate adverse effects of sildenafil by accelerating or decreasing its metabolism and clearance.

Trials of sildenafil to date have exploited its ability to cause rapid and potent vasodilatation resulting in improved hemodynamics. Acute administration of a single oral dose of sildenafil causes a significant decrease in MPAP and PVR with minimal or no affect on mean arterial pressure (MAP) and improvement, or a trend towards improvement, in cardiac output. The effect peaks at 60 minutes and lasts as long as 4 hours (Hoeper et al 2000; Ghofrani et al 2002a, 2002b; Lepore et al 2002; Michelakis et al 2002). Two studies found a dose-dependent relationship for changes in cardiac index (CI), pulmonary arterial pressure, and pulmonary vascular resistance index (PVRI) (Ghofrani et al 2002a, 2002b). One report describes a decrease in the ratio of PVR to systemic vascular resistance (SVR) at lower doses, suggesting selectivity for the pulmonary vasculature (Ghofrani et al 2002a). The magnitude of the effect in the pulmonary circulation is comparable to that of inhaled NO, iloprost, and prostacyclin (Hoeper et al 2000; Lepore et al 2002).

Vasodilators may improve hemodynamics, but treatments that inhibit or reverse vascular remodeling to slow inevitable disease progression are being sought. Sildenafil may prevent or reverse remodeling through NO and cGMP modulation of smooth muscle proliferation and apoptosis (Figure 1) (Garg and Hassid 1990; Lee et al 1996; Pollman et al 1996; Chiche et al 1998; Osinski et al 2001). Clinical data with adequate follow-up time in patients treated with sildenafil are so far inadequate to address this possibility, but limited data from early studies suggest that it is plausible and mechanistically sound.

In one report, sildenafil inhibited platelet derived growth factor (PDGF)-induced DNA synthesis and cell proliferation, and inhibited hypoxia-induced cell proliferation. Increased levels of cGMP indirectly lead to increased levels of cAMP which may suppress transcription of DNA, activate anti-proliferative protein kinases, and inhibit PDGF activity (Tantini et al 2005). In vivo, sildenafil has been shown to prevent and reverse remodeling in monocrotaline-, hypoxia-, and overcirculation-induced animal models of PAH (Sebkhi et al 2003; Itoh et al 2004; Rondelet et al 2004; Schermuly et al 2004). In humans, PDE 5 expression was increased in remodeled pulmonary arteries from patients with idiopathic PAH and familial PAH. Stimulation of the cGMP pathway inhibited DNA synthesis and cell proliferation and promoted apoptosis in isolated pulmonary artery smooth muscle cells, an effect potentiated by sildenafil (Wharton et al 2005).

\section{Clinical applications}

The use of sildenafil to treat PH from a variety of causes has increased dramatically although, for many applications, only case reports or small series offer evidence of safety and efficacy. Future large, well designed trials are critical to direct physicians in the treatment of unstudied populations who might benefit from sildenafil.

\section{PAH}

Three randomized controlled trials have been performed to evaluate the use of sildenafil in patients with PAH (Table 2). Ten patients with New York Heart Association (NYHA) classification $>2$, pulmonary artery systolic pressure (PASP) $\geq 35 \mathrm{mmHg}$, normal left ventricular function, and no reversible cause of $\mathrm{PAH}$ were included in a prospective randomized, placebo-controlled cross over study to evaluate the effects of short-term sildenafil treatment. PAH was idiopathic (3), or related to interstitial lung disease (2), chronic thromboembolic disease (1), or chronic left to right shunt (3). Patients in the sildenafil group had an improvement in the primary endpoint of 6 minute walk distance from 163.9 to $266.7 \mathrm{~m}(\mathrm{p}<0.005)$ compared with no change with placebo. Changes in secondary endpoints with sildenafil treatment included a decrease in the Borg dyspnea index and PASP from 5.2 to $3.6(\mathrm{p}<0.01)$ and 80.8 to $55.3 \mathrm{mmHg}(\mathrm{p}<0.05)$ respectively (Bharani et al 2003).

In another trial, 22 patients with NYHA class II-III and PASP $>70 \mathrm{mmHg}$ by echocardiography were randomized to 6 weeks of sildenafil or placebo with subsequent crossover. The primary endpoint of exercise time decreased non-significantly compared with baseline in the placebo first group, but increased from 451 to 698 seconds during sildenafil $(\mathrm{p}<0.001)$ then decreased to 527 seconds during placebo ( $p<0.001$ compared with baseline) in the sildenafil first group. When the groups were combined, exercise time increased from 475 seconds after placebo to 686 seconds after 6 weeks of sildenafil $(p<0.0001)$. Cardiac index $(2.8-$ 
Table 2 Summary of randomized controlled trials of sildenafil in the treatment of PAH (Bharani et al 2003; Sastry et al 2004; Galiè et al 2005)

\begin{tabular}{|c|c|c|c|}
\hline & Baharani 2003 & Sastry 2004 & Galiè 2005 \\
\hline Trial design & $\begin{array}{l}\text { Randomized, placebo controlled, } \\
\text { double blind, crossover }\end{array}$ & $\begin{array}{l}\text { Randomized, placebo } \\
\text { controlled, double blind, } \\
\text { crossover }\end{array}$ & $\begin{array}{l}\text { Randomized double blind, placebo } \\
\text { controlled }\end{array}$ \\
\hline No (male) & $9(4)$ & $22(10)$ & $277(68)$ \\
\hline Etiology (number) & $\begin{array}{l}\text { Idiopathic PAH (3) } \\
\text { Left to right shunt (3) } \\
\text { Thromboembolism (I) } \\
\text { ILD (2) }\end{array}$ & Idiopathic PAH (22) & $\begin{array}{l}\text { Idiopathic PAH (I } 75) \\
\text { CTD (84) } \\
\text { Left to right shunt (I8) }\end{array}$ \\
\hline Duration & 2 weeks & 6 weeks & 12 weeks \\
\hline Primary outcome & $\begin{array}{l}6 \text { min walk } 170 \mathrm{~m} \text { at end of } \\
\text { placebo phase vs } 266 \mathrm{~m} \text { at end } \\
\text { of sildenafil phase, } \mathrm{p}<0.005\end{array}$ & $\begin{array}{l}\text { Exercise treadmill time } \\
475 \pm 168 \mathrm{~s} \text { at end of placebo } \\
\text { phase vs } 686 \pm 224 \mathrm{~s} \text { at end of } \\
\text { sildenafil phase, } \mathrm{p}<0.000 \text { I }\end{array}$ & $\begin{array}{l}\text { Placebo corrected increase in mean } \\
6 \text { min walk distance } 20,40 \text {, and } \\
80 \mathrm{mg} ; 45,46 \text {, and } 50 \mathrm{~m}(\mathrm{p}<0.00 \mathrm{I})\end{array}$ \\
\hline Secondary outcomes & $\begin{array}{l}\text { Significant improvement in Borg } \\
\text { dyspnea score and PASP }\end{array}$ & $\begin{array}{l}\text { Significant improvement in } \\
\text { cardiac index and QOL, } \\
\text { no change in PASP }\end{array}$ & $\begin{array}{l}\text { Significant improvement in } \mathrm{mPAP}, \mathrm{Cl} \\
\text { ( } 40 \text { and } 80 \mathrm{mg} \text { dose), } \mathrm{PVR}, \mathrm{WHO} \\
\text { functional class, no change in time to } \\
\text { worsening or Borg dyspnea scale }\end{array}$ \\
\hline Adverse effects & None reported & Similar to placebo & $\begin{array}{l}\text { Increased rate of headache and } \\
\text { epistaxis in sildenafil group }\end{array}$ \\
\hline
\end{tabular}

Abbreviations: CTD, connective tissue disease; ILD, interstitial lung disease; mPAP, mean pulmonary artery pressure; PAH, pulmonary arterial hypertension; PASP, pulmonary artery systolic pressure; PVR, pulmonary vascular resistance; QOL, quality of life.

$\left.2.45 \mathrm{~L} \cdot \mathrm{min}^{-1} \cdot \mathrm{m}^{-2}, \mathrm{p}<0.0001\right)$ and quality of life measures for dyspnea and fatigue improved although there was no significant difference in PASP (Sastry et al 2004).

The Super-1 trial was an international multicenter, randomized, blinded, controlled study involving 278 patients with symptomatic PAH that was idiopathic, associated with connective tissue disease, or repaired congenital systemic to pulmonary shunts. Patients were stratified according to baseline walk distance and etiology of PAH and randomized to placebo or sildenafil at a dose of 20,40 , or $80 \mathrm{mg} 3$ times daily for 12 weeks followed by a long-term extension study of sildenafil $80 \mathrm{mg}$. For the primary outcome of exercise capacity, there was a significant improvement in 6 minute walk distance in all patients taking sildenafil (Table 3). There was no significant difference in time to clinical worsening, but fewer patients taking sildenafil were hospitalized for worsening PAH. One patient developed left ventricular dysfunction and one patient had postural hypotension thought to be related to sildenafil (Galiè et al 2005). There was a non-significant trend towards improved hemodynamics with higher doses and the extension study showed favorable results of long-term treatment with $80 \mathrm{mg}$.

The only comparative treatment trial studied patients with idiopathic or collagen vascular disease associated PAH who were symptomatic despite maximal conventional therapy. For the primary outcome of right ventricular mass, there was a significant improvement in baseline versus sildenafil but no difference between baseline and bosentan or between sildenafil and bosentan. There were differences between treatment groups (sildenafil superior) only in 6

Table 3 Results of the Super-I trial showing improvements in hemodynamics and 6 minute walk test with use of sildenafil

\begin{tabular}{|c|c|c|c|c|}
\hline Effect at 8 weeks & $\begin{array}{l}\text { Placebo ( } 95 \% \\
\text { confidence interval) }\end{array}$ & $\begin{array}{l}20 \mathrm{mg}(95 \% \\
\text { confidence interval) }\end{array}$ & $\begin{array}{l}40 \mathrm{mg}(95 \% \\
\text { confidence interval) }\end{array}$ & $\begin{array}{l}80 \mathrm{mg}(95 \% \\
\text { confidence interval) }\end{array}$ \\
\hline $\begin{array}{l}6 \text { minute walk distance } \\
\text { (placebo corrected, in } \\
\text { meters) }\end{array}$ & & $45(21,70)$ & $46(20,72)$ & $50(23,77)$ \\
\hline $\begin{array}{l}\text { Mean pulmonary artery } \\
\text { pressure (mmHG) }\end{array}$ & $0.6(-0.8,2.0)$ & $-2.1(-4.3,0.0)$ & $-2.6(-4.4,-0.9)$ & $-4.7(-6.7,-2.8)$ \\
\hline $\begin{array}{l}\text { Cardiac index } \\
\left(\mathrm{L} \cdot \mathrm{min}^{-1} \cdot \mathrm{m}^{-2}\right)\end{array}$ & $-0.02(-0.17,0.13)$ & $0.21(0.04,0.8)$ & $0.24(0.05,0.42)$ & $0.37(0.20,0.55)$ \\
\hline PVR (dynes $\cdot \mathrm{s}^{-1} \cdot \mathrm{cm}^{-5}$ ) & $49(-54,153)$ & $-22(-2 \mid 7,-27)$ & $-143(-218,-69)$ & $-261(-365,-157)$ \\
\hline
\end{tabular}

Abbreviations: PVR, pulmonary vascular resistance. 
minute walk distance and quality of life score (Wilkins et al 2005).

The Super-1 trial is the only high quality, randomized, blinded controlled study that has shown a benefit of treatment with sildenafil. The study population was made up largely of individuals with idiopathic $\mathrm{PAH}$, and subgroup analysis of patients with other diagnoses failed to show a statistically significant improvement in 6 minute walk distance at a dose of $20 \mathrm{mg} 3$ times daily. Some experts have expressed concern that FDA approval of only the 20 -mg dose could result in some patients being harmed by undertreatment (Hoeper et al 2006). For now, data are adequate to support treatment of PAH with sildenafil. Although accumulating evidence is encouraging and reported toxicities are limited, sildenafil treatment for $\mathrm{PH}$ other than PAH should be considered experimental.

\section{HIV-associated PAH}

HIV-associated PAH is estimated to occur in $0.5 \%$ of infected patients with a mortality approaching 50\% at 36 months (Speich et al 1991; Pellicelli et al 2001). Pathologic examination shows plexiform lesions and the disease is thought to be mediated by endothelial dysfunction secondary to the host immune response or HIV therapy. Calcium channel blocker therapy is not successful and patients are particularly susceptible to adverse effects of prostacyclin infusion and to bosentan associated hepatic toxicity. Treatment of HIV-associated PAH with sildenafil has been limited due to interactions between sildenafil and protease inhibitors and recreational use of street drugs such as amyl nitrate. Successful treatment with sildenafil has been reported in 3 adult patients with $\mathrm{HIV}$-associated PAH (Schumacher et al 2001; Carlsen et al 2002; Alp et al 2003). All three patients showed improvements in hemodynamics, functional class, and symptoms. Treatment of one 18-monthold patient with supra systemic pulmonary artery pressures and right heart dysfunction has also been reported. Twelve months of sildenafil resulted in near resolution of right heart abnormalities by echocardiography (Wong et al 2006).

\section{Hemolysis associated PAH}

PAH affects approximately $30 \%$ of patients with sickle cell anemia (Sutton et al 1994; Castro 1996; Castro et al 2003; Castro and Gladwin 2005) and has been identified as a major independent predictor of death (Gladwin et al 2004). A hemolysis-mediated decrease in NO bioavailability (Reiter et al 2002) increased production of endothelin-1 and free radicals, platelet activation, and endothelial dysfunction along with chronic hypoxia, and a prothrombotic state occurs in hemolytic disorders resulting in PAH (Machado and Gladwin 2005). Because of the abnormally high rate of NO destruction central to the pathophysiology of these disorders, sildenafil may be a uniquely well suited treatment choice.

One small study evaluated the efficacy and safety of sildenafil in 7 patients with thalassemia intermedia, thalassemia major, and sickle cell thalassemia with advanced disease despite maximal conventional therapy. All patients experience progressive hemodynamic and symptomatic improvement. No patients reported adverse effects and no patients stopped the drug due to adverse effects (Derchi et al 2005).

In another small, uncontrolled, open label trial we evaluated the effects of sildenafil on hemodynamics and functional status in patients with mild to moderate PAH and impaired exercise capacity associated with sickle cell disease. Acute administration of sildenafil during right heart catheterization resulted in a statistically significant change of mPAP of $-26 \%$, PVR of $-57 \%$, CI of $45 \%$, and PVR to SVR ratio of $-38 \%$, suggesting preferential pulmonary vasodilation. Among 12 patients treated chronically, pulmonary artery systolic pressure (PASP) measured by echocardiogram and 6 minute walk improved significantly from 50 to $41 \mathrm{mmHg}$ and 384 to $462 \mathrm{~m}$ respectively. One patient had to stop treatment due to headaches (Machado et al 2005). Based on these results, a large National Heart Lung and Blood Institute sponsored randomized trial of sildenafil in sickle cell anemia-associated PAH will be launched in the next 12 months.

\section{Portopulmonary hypertension}

Pulmonary hypertension with a mPAP of $40-45 \mathrm{mmHg}$ prior to liver transplantation is associated with a mortality of $70 \%$ $80 \%$ (Makisalo et al 2004) and successful treatment of PH is required prior to listing for transplant. End stage liver disease precludes the use of bosentan and prostacyclin use is especially challenging in this population. However, concerns have been raised about the interaction of the potential antiplatelet effect of sildenafil and bleeding diathesis that results from liver disease.

The literature contains reports of 2 patients with primary billiary cirrhosis hepatitis $\mathrm{C}$ complicated by portopulmonary hypertension who were treated with sildenafil. Both patients responded well allowing liver transplantation to proceed. One patient developed a hematoma post-operatively that may have been secondary to the antiplatelet effects of sildenafil (Makisalo et al 2004; Chua et al 2005). Another 
small trial studied 14 patients with portopulmonary hypertension treated with sildenafil or inhaled iloprost plus sildenafil. Patients had a statistically significant improvement in PVR and 6 minute walk distance at 3 and 12 months follow up. Two patients died as a result of their underlying disease but there were no adverse bleeding events related to sildenafil (Reichenberger et al 2006).

\section{Persistent $\mathrm{PH}$ of the newborn}

Persistent PH of the newborn (PPHN) occurs when PVR remains elevated after birth resulting in right to left shunting and hypoxemia. The incidence is $0.43-6.8 / 1000$ live births and it has a mortality rate of $10 \%-20 \%$ (Travadi and Patole 2003). Management is supportive and inhaled NO and extra corporeal membrane oxygenation (ECMO) are indicated if they are available (Schreiber et al 2003). Sildenafil could provide a feasible and cost-effective alternative to inhaled NO and ECMO (Kumar 2002). Three cases of children between 7 days and 5 months of age with bronchopulmonary dysplasia, an intracardiac shunt, and acute respiratory failure treated with sildenafil have been published. All patients were critically ill, requiring maximal available hemodynamic and respiratory support. After beginning sildenafil, all patients had rapid improvement (Chaudhari et al 2005; Hon et al 2005; Juliana and Abbad 2005).

\section{Pediatric patients with PAH}

One open label single drug trial evaluated the effects of 12 months of sildenafil-treatment pediatric patients with idiopathic PAH, post op congenital heart defect repair, and Eisenmenger syndrome. Right heart catheterization in 9 showed a significant reduction in mPAP from 60 to $50 \mathrm{mmHg}$ and a decrease in pulmonary vascular resistance index from 15 to 12 wood units $/ \mathrm{m}^{2}$ without a change in systemic hemodynamics. Six minute walk distance increased from a mean of $278 \mathrm{~m}$ to $432 \mathrm{~m}$. There were no deaths during the 12 -month study period compared with $37 \%$ survival in historical controls (Humpl et al 2005).

\section{Combination therapy in PAH}

Data on combination therapy in $\mathrm{PH}$ is limited, but it has already become common practice among some physicians (Hoeper and Dinh-Xuan 2004). Similar to therapy of congestive heart failure, patients may benefit from synergistic effects of drugs with disparate mechanisms of action. Numerous small trials have begun exploring the utility of this approach.
In one study, exercise treadmill time, dyspnea fatigue score, and WHO functional class improved in 8 patients on chronic, subcutaneous treprostenol treated with oral sildenafil (Gomberg-Maitland et al 2005). Another study examined 30 patients with idiopathic PAH, CREST, congenital vascular defect, or chronic thromboembolic disease treated with inhaled $\mathrm{NO}$ followed by inhaled iloprost then by sildenafil alone or inhaled iloprost plus sildenafil. With combined iloprost and sildenafil therapy, the effect on mPAP, PVR, and CI was more pronounced and longer lasting, and the vasodilatory response was greater than for the sum of the individual therapies, suggesting treatment synergy (Ghofrani et al 2002). Ghofrani and colleagues also studied 14 patients deteriorating on inhaled iloprost and found that the addition of sildenafil resulted in an increased 6 minute walk distance, decreased mPAP, decreased PVR, and improved functional class (Ghofrani et al 2003). Lastly, a study of beraprost and sildenafil resulted in a more potent lowering of the mPAP and a longer treatment effect than beraprost alone (Ikeda et al 2005).

A study of goal-based therapy versus historical controls treated with inhaled or i.v. prostaglandins involved treatment with bosentan followed by the addition of sildenafil, inhaled iloprost, or change to intravenous iloprost, to achieve a 6 minute walk distance $>380 \mathrm{~m}$, a peak oxygen uptake $>10.4 \mathrm{~mL} \cdot \mathrm{min}^{-1} \cdot \mathrm{kg}^{-1}$, and a peak SBP during exercise of $>120 \mathrm{mmHg}$. Among 123 patients enrolled, 43.2\% met treatment goals on 2 drugs, $16.1 \%$ on 3 , and $4.2 \%$ required intravenous iloprost. Mortality (23.8\% vs $13.8 \%)$ and transplantation-free survival were better in the goal based treatment group (Hoeper et al 2005).

\section{PH}

\section{Heart failure, cardiac surgery, and cardiac transplant}

Pulmonary hypertension is a complication of heart failure from left ventricular dysfunction associated with increased mortality and is a contraindication to heart transplant (Erickson et al 1990; Costard-Jackle and Fowler 1992; Delgado et al 2001). Sildenafil has been used in the preoperative period in 2 studies to test vasoreacticity (Alaeddini et al 2004) and to successfully treat established $\mathrm{PH}$ that would have otherwise been a contraindication to heart transplant (Gómez-Moreno et al 2005).

$\mathrm{PH}$ can also complicate cardiac and peripheral vascular surgery and is thought to be due to pulmonary endothelial dysfunction related to cardiopulmonary bypass and other 
factors (Hayward et al 1999; Fung et al 2005). Standard therapies include beta agonists, PDE III inhibitors, and intravenous or inhaled nitrovasodilators (Trachte et al 2005). Treatment with sildenafil, however, is growing more common even in the absence trial data to support its use (Madden and Crerar-Gilbert 2005).

Three reports describe the use of sildenafil for worsening $\mathrm{PH}$ in post-operative patients requiring multiple pressors and inotropic support. In one, sildenafil decreased the mPAP from 58 to $29 \mathrm{mmHg}$ and the PCWP from 32 to $18 \mathrm{mmHg}$ after coronary bypass and mitral annuloplasty, improving systemic blood pressure. In the second, sildenafil was given intra-operatively during an aortic valve replacement for a mPAP of $90 \mathrm{mmHg}$ accompanied by systemic hypotension despite epinephrine, milrinone resulting in a decrease in mPAP to $50 \mathrm{mmHg}$ (Madden and Crerar-Gilbert 2005). In a third, patients' status post mitral valve surgery or left ventricular assist device (LVAD) placement who received sildenafil for elevated PAP had significant improvement in MAP, mPAP, and PVRI. SVRI decreased, but the PVR/SVR ratio decreased consistent with a preferential pulmonary vasodilation (Trachte et al 2005).

$\mathrm{PH}$ is common in the peri-operative period in pediatric cardiac surgery and may respond to treatment with sildenafil. In 12 children with an increased PVRI after cardiac surgery, sildenafil resulted in a significant decrease in PVRI that was greater than that achieved with NO alone, and PVRI/ SVRI ratio was consistent with pulmonary selectivity. The addition of NO to sildenafil did not result in a greater benefit. A significant increase in shunt fraction from $16.5 \%$ to $25.5 \%$ occurred after treatment with sildenafil; however, no patients experienced hypoxia and dead space ventilation remained unchanged. The authors concluded that treatment with inhaled NO and sildenafil were equivalent (Schulze-Neick et al 2003).

A prospective study randomized 15 ventilated infants after ventricular or atrial septal defect closure to receive NO followed by sildenafil or the same therapies in the reverse order. Although sildenafil treatment decreased mPAP and PVRI, the study was stopped early due to worsening oxygenation and systemic hypotension associated with sildenafil (Stocker et al 2003).

\section{Pulmonary thromboembolic disease}

Sildenafil has been used in a case of acute pulmonary embolism and right heart failure in the setting of chronic PAH from right to left shunt. A 58-year-old woman hospitalized with a massive tri-lobe pulmonary embolism was found to have a PASP of $100 \mathrm{mmHg}$ accompanied by severe refractory hypoxemia. Sildenafil was started and after 2 hours, PVRI had decreased from 700 to 425 dynes $\cdot \mathrm{s}^{-1} \cdot \mathrm{cm}^{-5} \cdot \mathrm{m}^{-2}$ and CI had increased from 2.1 to $3.2 \mathrm{~L} \cdot \mathrm{min}^{-1} \cdot \mathrm{m}^{-2}$ with no change in mPAP (Ganiere et al 2006).

The effects of sildenafil were studied in 12 patients with severe chronic thromboembolic PH (CTEPH) who were not candidates for thrombectomy. Average baseline mPAP, PVRI, and CI were $52.6 \mathrm{mmHg}, 1935$ dynes $\cdot \mathrm{s}^{-1} \cdot \mathrm{cm}^{-5} \cdot \mathrm{m}^{-2}$ and $2.01 \mathrm{~min}^{-1} \cdot \mathrm{m}^{-2}$. After approximately 6.5 months of sildenafil treatment, a statistically significant improvement had occurred in all parameters with a mPAP, PVRI, and CI of $44.9 \mathrm{mmHg}, \quad 1361$ dynes $\cdot \mathrm{s}^{-1} \cdot \mathrm{cm}^{-5} \cdot \mathrm{m}^{-2}$, and $2.4 \mathrm{~min}^{-1} \cdot \mathrm{m}^{-2}$, respectively, and no adverse events (Ghofrani et al 2003b).

\section{Pulmonary fibrosis associated $\mathrm{PH}$}

Fibrotic lung disease is frequently associated with $\mathrm{PH}$ and can be a source of significant morbidity and mortality (King et al 2001). In patients with interstitial lung disease, systemic administration of vasodilators can increase blood flow to poorly ventilated areas overriding physiologic hypoxic vasoconstriction, leading to worsening V/Q mismatch and shunting with a resultant decrease in arterial oxygenation. Nebulized or inhaled therapies avoid this problem by distributing preferentially to well ventilated alveoli, but delivery systems can be costly and cumbersome to use.

A randomized, open label trial examined the effects of acute administration of oral sildenafil on V/Q matching in interstitial lung disease. Sixteen patients with fibrotic lung disease (idiopathic pulmonary fibrosis, CREST, systemic sclerosis, silicosis, and extrinsic allergic alveolitis) and an mPAP greater than $35 \mathrm{mmHg}$ underwent vasodilator testing with inhaled NO and were randomized to receive intravenous epoprostenol or oral sildenafil. Inhaled NO, epoprostenol, and sildenafil all resulted in a significant decrease in mPAP and PVRI. Cardiac output remained nearly constant in the NO group, while it increased in the sildenafil group and increased to a greater extent in the epoprostenol group. Inhaled NO caused a non-significant decrease in pulmonary shunt flow and a moderate increase in the partial pressure of oxygen. Epoprostenol resulted in a large, significant $16.8 \%$ increase in shunt flow, a decrease in the $\mathrm{PaO}_{2}$, increased perfusion to low V/Q areas, and an increase in mean ventilation. Oral sildenafil resulted in a non-significant decrease in shunt flow and a rise in the partial pressure of oxygen. The authors concluded that sildenafil 
induces vasodilation selectively in well ventilated lung units by acting through intrinsic vasodilator/vasoconstrictor pathways (Ghofrani et al 2002c). There are, however, no data evaluating the chronic effects of sildenafil on $\mathrm{PH}$ related to alveolar hypoxemia.

\section{Altitude-associated $\mathrm{PH}$}

High altitude pulmonary edema (HAPE) is a syndrome that occurs shortly after ascent due to a deranged response to hypoxia and hypobaria in susceptible individuals and accounts for the majority of deaths related to high altitude (Schäfer and Bauersachs 2002). The mechanism is unclear but may be related to an abnormally pronounced degree of pulmonary vasoconstriction secondary to abnormalities in vasodilators and vasoconstrictors (such as $\mathrm{NO}$ and endothelin-1), pulmonary capillary tears and leaks, exaggerated sympathetic tone, and induction and release of inflammatory cytokines (Basnyat and Murdoch 2003). Treatment with portable hyperbaric chambers, supplemental oxygen, and nifedipine have been studied in small trials, but their utility is limited by availability and adverse effects. Several trials have examined the role of sildenafil in attenuating the effects of alveolar hypoxia on pulmonary artery pressures and in improving exercise tolerance.

Ghofrani et al examined the response of exercise pulmonary hemodynamics to sildenafil during hypoxic conditions at sea level and at the Mount Everest base camp. When compared with baseline, all participants had a significant pulmonary hypertensive response to hypoxic conditions at sea level and at Everest base camp. The effect was augmented by exercise but significantly blunted by treatment with a one time dose of $50 \mathrm{mg}$ of sildenafil (increase in mPAP: placebo group sea level hypoxia rest $+75 \%$, exercise $+145 \%$; Everest rest $+57 \%$, exercise $+92 \%$; sildenafil sea level hypoxia rest $+26 \%$, exercise $+108 \%$; Everest rest $+26 \%$, exercise $+57 \%$ ). Sildenafil treatment also resulted in a statistically significant improvement in exercise tolerance under hypoxic or high altitude conditions (hypoxic exercise $+20 \%$, Everest exercise $+11 \%$ ) without affecting systemic blood pressure, heart rate, or oxygen saturation (Ghofrani et al 2004).

Another trial examined the effects of sildenafil on hemodynamics in 12 healthy men at sea level, and at $4350 \mathrm{~m}$ before and after treatment with sildenafil. The sildenafil group had a significantly lower heart rate, higher oxygen saturation, and lower PASP compared with the placebo group. During exercise testing, peak oxygen consumption was higher in the sildenafil group than the placebo group (Richalet et al 2005).

Chronic mountain sickness is a syndrome occurring with long-term exposure to altitude that can result in $\mathrm{PH}$ and right heart failure(Ge and Helun 2001). A randomized, controlled study evaluated the use of sildenafil to treat $\mathrm{PH}$ in residents of the Naryn region of Krygystan, 2500-4000 m a.s.l. Twenty-two patients with $\mathrm{PH}$ were randomized to treatment with a single dose and then chronic administration of placebo versus 25 or $100 \mathrm{mg}$ of sildenafil every 8 hours. Compared with placebo, there was a significant decrease in mPAP of 6.7 and $11.6 \mathrm{mmHg}$ after the first dose of sildenafil and at 12 weeks, respectively. Six minute walk and physical symptoms score improved significantly by $43.5 \mathrm{~m}$ and 10.4 points at 12 weeks compared with placebo. There was a trend towards a decrease in PVR in the treatment groups (Aldashev et al 2005).

\section{Conclusion}

Over the last two decades, enormous progress has been made in the treatment of patients with $\mathrm{PH}$ resulting in significant improvement in morbidity and mortality. One example of such advances was the advent of oral therapies for PAH. In this context, sildenafil has emerged as an effective first-line oral therapeutic agent for patients with symptomatic $\mathrm{PAH}$ who do not have indications for treatment with intravenous prostacyclin. Salutary effects that may play an important role in the clinical efficacy of sildenafil, but require further study include selective pulmonary vasodilation and antiremodeling properties. Sildenafil shows promise as a useful therapy in numerous case reports of $\mathrm{PH}$ from a variety of causes. With the exception of post-operative pediatric cardiac surgery patients, sildenafil has not been associated with significant adverse effects in any of the subtypes of $\mathrm{PH}$ for which it has been studied. Clarification of the role of sildenafil in forms of $\mathrm{PH}$ other than idiopathic $\mathrm{PAH}$ will require future well designed trials.

\section{Disclosures}

The authors have no conflicts of interest to declare.

\section{References}

Ahn HS, Foster M, Cable M, et al. 1991. Ca/cam-stimulated and cgmpspecific phosphodiesterases in vascular and non-vascular tissues. $A d v$ Exp Med Biol, 308:191-7.

Alaeddini J, Uber PA, Park MH, et al. 2004. Efficacy and safety of sildenafil in the evaluation of pulmonary hypertension in severe heart failure. Am J Cardiol, 94:1475-7. 
Aldashev AA, Kojonazarov BK, Amatov TA, et al. 2005. Phosphodiesterase type 5 and high altitude pulmonary hypertension. Thorax, 60:683-7.

Alp S, Schlottmann R, Bauer TT, et al. 2003. Long-time survival with hiv-related pulmonary arterial hypertension:A case report. Aids, 17:1714-5.

Barst RJ, McGoon M, Torbicki A, et al. 2004. Diagnosis and differential assessment of pulmonary arterial hypertension. $\mathrm{J} \mathrm{Am} \mathrm{Coll} \mathrm{Cardiol,}$ 43:40S-7S.

Barst RJ, Rubin LJ, Long WA, et al. 1996. A comparison of continuous intravenous epoprostenol (prostacyclin) with conventional therapy for primary pulmonary hypertension. The primary pulmonary hypertension study group. $N$ Engl J Med, 334:296-302.

Basnyat BB, Murdoch DRDR. 2003. High-altitude illness. Lancet, 361:1967-74.

Bharani A, Mathew V, Sahu A, et al. 2003. The efficacy and tolerability of sildenafil in patients with moderate-to-severe pulmonary hypertension. Indian Heart $J$, 55:55-9.

Boolell MM, Gepi-Attee SS, Gingell JJC, et al. 1996. Sildenafil, a novel effective oral therapy for male erectile dysfunction. Br J Urol, 78:25761.

Carlsen J, Kjeldsen K, Gerstoft J. 2002. Sildenafil as a successful treatment of otherwise fatal hiv-related pulmonary hypertension. Aids, 16:1568-9.

Castro O. 1996. Systemic fat embolism and pulmonary hypertension in sickle cell disease. Hematol Oncol Clin North Am, 10:1289-303.

Castro PF, Bourge RC, McGiffin DC, et al. 1998. Intrapulmonary shunting in primary pulmonary hypertension:An observation in two patients treated with epoprostenol sodium. Chest, 114:334-6.

Castro O, Gladwin MT. 2005. Pulmonary hypertension in sickle cell disease:Mechanisms, diagnosis, and management. Hematol Oncol Clin North Am, 19:881-96, vii.

Castro O, Hoque M, Brown BD. 2003. Pulmonary hypertension in sickle cell disease:Cardiac catheterization results and survival. Blood, 101:1257-61

Channick RN, Simonneau G, Sitbon O, et al. 2001. Effects of the dual endothelin-receptor antagonist bosentan in patients with pulmonary hypertension:A randomised placebo-controlled study. Lancet, 358:1119-23.

Chaudhari M, Vogel M, Wright C, et al. 2005. Sildenafil in neonatal pulmonary hypertension due to impaired alveolarisation and plexiform pulmonary arteriopathy. Arch Dis Child Fetal Neonatal Ed, 90:F527-8.

Chiche JD, Schlutsmeyer SM, Bloch DB, et al. 1998. Adenovirus-mediated gene transfer of cgmp-dependent protein kinase increases the sensitivity of cultured vascular smooth muscle cells to the antiproliferative and pro-apoptotic effects of nitric oxide/cgmp. J Biol Chem, 273:34263-71.

Chua R, Keogh A, Miyashita M. 2005. Novel use of sildenafil in the treatment of portopulmonary hypertension. J Heart Lung Transplant, 24:498-500.

Costard-Jackle A, Fowler MB. 1992. Influence of preoperative pulmonary artery pressure on mortality after heart transplantation:Testing of potential reversibility of pulmonary hypertension with nitroprusside is useful in defining a high risk group. $J$ Am Coll Cardiol, 19:48-54.

D'Alonzo GE, Barst RJ, Ayres SM, et al. 1991. Survival in patients with primary pulmonary hypertension. Results from a national prospective registry. Ann Intern Med, 115:343-9.

Delgado JF, Gomez-Sanchez MA, Saenz de la Calzada C, et al. 2001. Impact of mild pulmonary hypertension on mortality and pulmonary artery pressure profile after heart transplantation. J Heart Lung Transplant, 20:942-8.

Derchi G, Forni GL, Formisano F, et al. 2005. Efficacy and safety of sildenafil in the treatment of severe pulmonary hypertension in patients with hemoglobinopathies. Haematologica, 90:452-8.

Erickson KW, Costanzo-Nordin MR, O'Sullivan EJ, et al. 1990. Influence of preoperative transpulmonary gradient on late mortality after orthotopic heart transplantation. J Heart Transplant, 9:526-37.
Fung E, Fiscus RR, Yim AP, et al. 2005. The potential use of type-5 phosphodiesterase inhibitors in coronary artery bypass graft surgery. Chest, 128:3065-73.

Fuster V, Steele PM, Edwards WD, et al. 1984. Primary pulmonary hypertension:Natural history and the importance of thrombosis. Circulation, 70:580-7.

Ganiere V, Feihl F, Tagan D. 2006. Dramatic beneficial effects of sildenafil in recurrent massive pulmonary embolism. Intensive Care Med, 32:452-4.

Galiè N, Ghofrani HA, Torbicki A, et al. 2005. Sildenafil citrate therapy for pulmonary arterial hypertension. $N$ Engl J Med, 353:2148-57.

Galiè N, Manes A, Uguccioni L, et al. 1998. Primary pulmonary hypertension:Insights into pathogenesis from epidemiology. Chest, 114:184S-94S

Garg UC, Hassid A. 1990. Nitric oxide-generating vasodilators inhibit mitogenesis and proliferation of balb/c $3 \mathrm{t} 3$ fibroblasts by a cyclic gmpindependent mechanism. Biochem Biophys Res Commun, 171:474-9.

Ge R, Helun G. 2001. Current concept of chronic mountain sickness:Pulmonary hypertension-related high-altitude heart disease. Wilderness Environ Med, 12:190-4.

Ghofrani HA, Reichenberger F, Kohstall MG, et al. 2004. Sildenafil increased exercise capacity during hypoxia at low altitudes and at mount everest base camp:A randomized, double-blind, placebocontrolled crossover trial. Ann Intern Med, 141:169-77.

Ghofrani HA, Rose F, Schermuly RT, et al. 2003a. Oral sildenafil as longterm adjunct therapy to inhaled iloprost in severe pulmonary arterial hypertension. J Am Coll Cardiol, 42:158-64.

Ghofrani HA, Schermuly RT, Rose F, et al. 2003b. Sildenafil for longterm treatment of nonoperable chronic thromboembolic pulmonary hypertension. Am J Respir Crit Care Med, 167:1139-41.

Ghofrani HA, Wiedemann R, Rose F, et al. 2002a. Combination therapy with oral sildenafil and inhaled iloprost for severe pulmonary hypertension. Ann Intern Med, 136:515-22.

Ghofrani HA, Wiedemann R, Rose F, et al. 2002b. Sildenafil for treatment of lung fibrosis and pulmonary hypertension:A randomised controlled trial. Lancet, 360:895-900.

Ghofrani HA, Wiedemann R, Rose F, et al. 2002c. Sildenafil for treatment of lung fibrosis and pulmonary hypertension:A randomised controlled trial. Lancet, 360:895-900.

Gladwin MT, Sachdev V, Jison ML, et al. 2004. Pulmonary hypertension as a risk factor for death in patients with sickle cell disease. $N$ Engl J Med, 350:886-95.

Gomberg-Maitland M, McLaughlin V, Gulati M, et al. 2005. Efficacy and safety of sildenafil added to treprostinil in pulmonary hypertension. Am J Cardiol, 96:1334-6.

Gómez-Moreno S, Lage E, Hernández A, et al. 2005. Use of oral sildenafil in patients with irreversible pulmonary hypertension not eligible for heart transplantation. Transplant Proc, 37:1550-1.

Hayward CS, Kelly RP, Macdonald PS. 1999. Inhaled nitric oxide in cardiology practice. Cardiovasc Res, 43:628-38.

Hoeper MM, Dinh-Xuan AT. 2004. Combination therapy for pulmonary arterial hypertension:Still more questions than answers. Eur Respir $J, 24: 339-340$.

Hoeper MM, Markevych I, Spiekerkoetter E, et al. 2005. Goal-oriented treatment and combination therapy for pulmonary arterial hypertension. Eur Respir J, 26:858-63.

Hoeper MM, Olschewski H, Ghofrani HA, et al. 2000. A comparison of the acute hemodynamic effects of inhaled nitric oxide and aerosolized iloprost in primary pulmonary hypertension. German pph study group. J Am Coll Cardiol, 35:176-82.

Hoeper MM, Oudiz RJ, Peacock A, et al. 2004. End points and clinical trial designs in pulmonary arterial hypertension:Clinical and regulatory perspectives. J Am Coll Cardiol, 43:48S-55S.

Hoeper MM, Welte T, Izbicki G, et al. 2006. Sildenafil citrate therapy for pulmonary arterial hypertension. $N$ Engl J Med, 354:1091-3. 
Hon KL, Cheung KL, Siu KL, et al. 2005. Oral sildenafil for treatment of severe pulmonary hypertension in an infant. Biol Neonate, 88:10912.

Humpl T, Reyes JT, Holtby H, et al. 2005. Beneficial effect of oral sildenafil therapy on childhood pulmonary arterial hypertension:Twelve-month clinical trial of a single-drug, open-label, pilot study. Circulation, 111:3274-80.

Ikeda D, Tsujino I, Ohira H, et al. 2005. Addition of oral sildenafil to beraprost is a safe and effective therapeutic option for patients with pulmonary hypertension. J Cardiovasc Pharmacol, 45:286-9.

Itoh T, Nagaya N, Fujii T, et al. 2004. A combination of oral sildenafil and beraprost ameliorates pulmonary hypertension in rats. Am J Respir Crit Care Med, 169:34-8.

Juliana AE, Abbad FC. 2005. Severe persistent pulmonary hypertension of the newborn in a setting where limited resources exclude the use of inhaled nitric oxide:Successful treatment with sildenafil. Eur $J$ Pediatr, 164:626-9.

King TE, Jr., Tooze JA, Schwarz MI, et al. 2001. Predicting survival in idiopathic pulmonary fibrosis:Scoring system and survival model. Am J Respir Crit Care Med, 164:1171-81.

Kling J. 1998. From hypertension to angina to viagra. Modern Drug Discovery, 1:31, 33-4, 36, 38.

Kloner RA. 2004. Cardiovascular effects of the 3 phosphodiesterase-5 inhibitors approved for the treatment of erectile dysfunction. Circulation, 110:3149-55.

Kumar S. 2002. Indian doctor in protest after using Viagra to save "blue babies". BMJ, 325:181.

Lee SH, Channick RN. 2005. Endothelin antagonism in pulmonary arterial hypertension. Semin Respir Crit Care Med, 26:402-8.

Lee SL, Wang WW, Fanburg BL. 1996. Nitroprusside inhibits serotonininduced mitogenesis and tyrosine phosphorylation of smooth muscle cells. Am J Physiol, 270:L362-7.

Lepore JJ, Maroo A, Pereira NL, et al. 2002. Effect of sildenafil on the acute pulmonary vasodilator response to inhaled nitric oxide in adults with primary pulmonary hypertension. Am J Cardiol, 90:67780.

Machado RF, Martyr S, Kato GJ, et al. 2005. Sildenafil therapy in patients with sickle cell disease and pulmonary hypertension. Br J Haematol, 130:445-53.

Machado RF, Gladwin MT. 2005. Chronic sickle cell lung disease:New insights into the diagnosis, pathogenesis and treatment of pulmonary hypertension. Br J Haematol, 129:449-64.

Madden B, Crerar-Gilbert A. 2005. Pulmonary hypertension and sildenafil. Br J Anaesth, 95:562.

Makisalo H, Koivusalo A, Vakkuri A, et al. 2004. Sildenafil for portopulmonary hypertension in a patient undergoing liver transplantation. Liver Transpl, 10:945-50.

McGwin G Jr, Vaphiades MS, Hall TA, et al. 2006. Non-arteritic anterior ischaemic optic neuropathy and the treatment of erectile dysfunction. Br J Ophthalmol, 90:154-7.

McLaughlin VV, Shillington A, Rich S. 2002. Survival in primary pulmonary hypertension:The impact of epoprostenol therapy. Circulation, 106:1477-82.

Michelakis E, Tymchak W, Lien D, et al. 2002. Oral sildenafil is an effective and specific pulmonary vasodilator in patients with pulmonary arterial hypertension:Comparison with inhaled nitric oxide. Circulation, 105:2398-403.

Miyamoto S, Nagaya N, Satoh T, et al. 2000. Clinical correlates and prognostic significance of six-minute walk test in patients with primary pulmonary hypertension. Comparison with cardiopulmonary exercise testing. Am J Respir Crit Care Med, 161:487-92.

Morales A, Gingell C, Collins M, et al. 1998. Clinical safety of oral sildenafil citrate (Viagra $\left.{ }^{\circledR}\right)$ in the treatment of erectile dysfunction. Int J Impot Res, 10:69-73.

Osinski MT, Rauch BH, Schror K. 2001. Antimitogenic actions of organic nitrates are potentiated by sildenafil and mediated via activation of protein kinase a. Mol Pharmacol, 59:1044-50.
Pauvert O, Lugnier C, Keravis T, et al. 2003. Effect of sildenafil on cyclic nucleotide phosphodiesterase activity, vascular tone and calcium signaling in rat pulmonary artery. Br J Pharmacol, 139:513-22.

Pauvert O, Salvail D, Rousseau E, et al. 2002. Characterisation of cyclic nucleotide phosphodiesterase isoforms in the media layer of the main pulmonary artery. Biochem Pharmacol, 63:1763-72.

Pellicelli AM, Barbaro G, Palmieri F, et al. 2001. Primary pulmonary hypertension in hiv patients: A systematic review. Angiology, 52:3141.

Pietra GG, Edwards WD, Kay JM, et al. 1989. Histopathology of primary pulmonary hypertension. A qualitative and quantitative study of pulmonary blood vessels from 58 patients in the national heart, lung, and blood institute, primary pulmonary hypertension registry. Circulation, 80:1198-206.

Pollman MJ, Yamada T, Horiuchi M, et al. 1996. Vasoactive substances regulate vascular smooth muscle cell apoptosis. Countervailing influences of nitric oxide and angiotensin ii. Circ Res, 79:748-56.

Rabe KF, Tenor H, Dent G, et al. 1994. Identification of pde isozymes in human pulmonary artery and effect of selective pde inhibitors. Am J Physiol, 266:L536-43.

Reichenberger F, Voswinckel R, Steveling E, et al. 2006. Sildenafil treatment for portopulmonary hypertension. Eur Respir J, 28:563-7.

Reiter CD, Wang X, Tanus-Santos JE, et al. 2002. Cell-free hemoglobin limits nitric oxide bioavailability in sickle-cell disease. Nat Med, 8:1383-9.

Rich S, Kaufmann E, Levy PS. 1992. The effect of high doses of calciumchannel blockers on survival in primary pulmonary hypertension. $N$ Engl J Med, 327:76-81.

Richalet J-P, Gratadour P, Robach P, et al. 2005. Sildenafil inhibits altitudeinduced hypoxemia and pulmonary hypertension. Am J Respir Crit Care Med, 171:275-81.

Rondelet B, Kerbaul F, Van Beneden R, et al. 2004. Signaling molecules in overcirculation-induced pulmonary hypertension in piglets:Effects of sildenafil therapy. Circulation, 110:2220-5.

Rubin LJ. 1997. Primary pulmonary hypertension. NEngl J Med, 336:111-7.

Rubin LJ, Badesch DB, Barst RJ, et al. 2002. Bosentan therapy for pulmonary arterial hypertension. $N$ Engl J Med, 346:896-903.

Sastry BKS, Narasimhan C, Reddy NK, et al. 2004. Clinical efficacy of sildenafil in primary pulmonary hypertension:A randomized, placebocontrolled, double-blind, crossover study. J Am Coll Cardiol, 43:114953.

Schäfer A, Bauersachs J. 2002. High-altitude pulmonary edema:Potential protection by red wine. Nutr Metab Cardiovasc Dis, 12:306-10.

Schermuly RT, Kreisselmeier KP, Ghofrani HA, et al. 2004. Chronic sildenafil treatment inhibits monocrotaline-induced pulmonary hypertension in rats. Am J Resp Crit Care Med, 169:39-45.

Schreiber MD, Gin-Mestan K, Marks JD, et al. 2003. Inhaled nitric oxide in premature infants with the respiratory distress syndrome. $N$ Engl $J$ Med, 349:2099-107.

Schulze-Neick I, Hartenstein P, Li J, et al. 2003. Intravenous sildenafil is a potent pulmonary vasodilator in children with congenital heart disease. Circulation, 108:167II-73.

Schumacher YO, Zdebik A, Huonker M, et al. 2001. Sildenafil in hivrelated pulmonary hypertension. Aids, 15:1747-8.

Sebkhi A, Strange JW, Phillips SC, et al. 2003. Phosphodiesterase type 5 as a target for the treatment of hypoxia-induced pulmonary hypertension. Circulation, 107:3230-5.

Simonneau G, Galie N, Rubin LJ, et al. 2004. Clinical classification of pulmonary hypertension. $J$ Am Coll Cardiol, 43:5S-12S.

Sitbon O, Humbert M, Jais X, et al. 2005. Long-term response to calcium channel blockers in idiopathic pulmonary arterial hypertension. Circulation, 111:3105-11.

Speich R, Jenni R, Opravil M, et al. 1991. Primary pulmonary hypertension in hiv infection. Chest, 100:1268-71.

Stocker C, Penny DJ, Brizard CP, et al. 2003. Intravenous sildenafil and inhaled nitric oxide:A randomised trial in infants after cardiac surgery. Intensive Care Med, 29:1996-2003. 
Sutton LL, Castro O, Cross DJ, et al. 1994. Pulmonary hypertension in sickle cell disease. Am J Cardiol, 74:626-8.

Tantini B, Manes A, Fiumana E, et al. 2005. Antiproliferative effect of sildenafil on human pulmonary artery smooth muscle cells. Basic Res Cardiol, 100:131-8.

Trachte AL, Lobato EB, Urdaneta F, et al. 2005. Oral sildenafil reduces pulmonary hypertension after cardiac surgery. Ann Thorac Surg, 79:194-7; discussion 194-7.

Travadi JN, Patole SK. 2003. Phosphodiesterase inhibitors for persistent pulmonary hypertension of the newborn:A review. Pediatr Pulmonol, 36:529-35.
Wharton J, Strange JW, Moller GMO, et al. 2005. Antiproliferative effects of phosphodiesterase type 5 inhibition in human pulmonary artery cells. Am J Respir Crit Care Med, 172:105-13.

Wilkins MR, Paul GA, Strange JW, et al. 2005. Sildenafil versus endothelin receptor antagonist for pulmonary hypertension (seraph) study. Am J Respir Crit Care Med, 171:1292-7.

Wong AR, Rasool AH, Abidin NZ, et al. 2006. Sildenafil as treatment for human immunodeficiency virus-related pulmonary hypertension in a child. J Paediatr Child Health, 42:147-8. 